\title{
Preparation and Properties of a
} Polycyclic $p$-Quinodimethane with Two Oxygen Bridges and its Radical Cation in Comparison with the Isomeric $o$ - Quinodimethane

Chihiro Sato, Shuichi Suzuki, Keiji Okada, Masatoshi Kozaki

\begin{tabular}{|c|l|}
\hline Citation & Chemistry - An Asian Journal. 13(23); 3729-3736 \\
\hline Issue Date & 2018-12-04 \\
\hline Type & Journal Article \\
\hline Textversion & Author \\
\hline \multirow{2}{*}{ Relation } & $\begin{array}{l}\text { This is the peer reviewed version of the following article: Chemistry - An Asian Journal } \\
\text { Vol.13, Issu.23, p.3729-3736, which has been published in final form at } \\
\text { https://doi.org/10.1002/asia.201801269. This article may be used for non-commercial } \\
\text { purposes in accordance with Wiley Terms and Conditions for Use of Self-Archived Versions. }\end{array}$ \\
\hline DOI & \begin{tabular}{l} 
10.1002/asia.201801269 \\
\hline
\end{tabular} \\
\hline
\end{tabular}

\author{
Self-Archiving by Author(s) \\ Placed on: Osaka City University
}

SATO, C., SUZUKI, S., OKADA, K., \& KOZAKI, M. (2018). Preparation and Properties of a Polycyclic p -Quinodimethane with Two Oxygen Bridges and its Radical Cation in Comparison with the Isomeric o -Quinodimethane. Chemistry - An Asian Journal. 13, 3729-3736. doi:10.1002/asia.201801269 


\title{
Preparation and Properties of a Polycyclic $p$-Quinodimethane with Two Oxygen Bridges and its Radical Cation in Comparison with the Isomeric o-Quinodimethane
}

\author{
Chihiro Sato, ${ }^{[a]}$ Shuichi Suzuki, ${ }^{[a, b]}$ Keiji Okada, ${ }^{[a, c]}$ and Masatoshi Kozaki ${ }^{*,[a, c]}$ \\ Dedication ((optional))
}

\begin{abstract}
We prepared an electron-rich p-quinodimethane compound, 2,9-dibromo-7,14-dimesityl-5,12-dioxapentacene (1). The quinoidal character was clarified by bond-length alternation in the central ring. Clear vibrational structures in both absorption and emission bands and small Stokes shift indicate the rigid dioxapentacene framework. The reversible redox waves of 1 were observed at +0.14 and $+0.69 \mathrm{~V}$ vs $\mathrm{Fc}^{+} / \mathrm{Fc}$, respectively. Radical

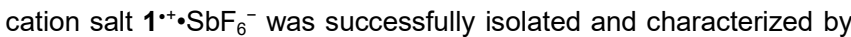
means of X-ray structural analysis and ESR and UV-vis-near infrared absorption spectroscopies. The molecular structure and electronic properties of the neutral and radical cation species were compared to those of the isomeric o-quinodimethane.
\end{abstract}

\section{Introduction}

Quinoidal conjugated systems have intrinsic amphoteric redox ability because they can form aromatic rings through both oxidation and reduction processes (Figure 1). ${ }^{1}$ Absorption and emission bands of the quinoidal conjugated systems generally appear in longer wavelength regions compared to the corresponding non-quinoidal neutral aromatic systems. Because of these unique properties, quinoidal compounds have been widely used as organic semiconducting, magnetic, and optical materials. ${ }^{2}$ Interestingly, the most widely used quinoidal systems are strong electron acceptors such as 7,7,8,8-tetracyano- $p$ quinodimethane (TCNQ). ${ }^{3}$ On the other hand, a fewer quinoidal compounds with strong electron-donating ability have been investigated. Recently, some polycyclic compounds with $p$ quinodimethane ( $p Q D M)$ frameworks were reported as $p$-type (hole-transporting) semiconducting materials. ${ }^{4}$ In addition, a few

[a] Dr. C. Sato, Dr. S. Suzuki, Prof. Dr. K. Okada, Prof. Dr. M. Kozaki Graduate School of Science

Osaka City University

3-3-138, Sugimoto, Sumiyoshi-ku

Osaka 558-8585 (Japan)

E-mail:kozaki@sci.osaka-cu.ac.jp

[b] Dr. S. Suzuki

Present address: Graduate School of Engineering Science

Osaka University

Machikaneyama, Toyonaka, Osaka 560-8531 (Japan)

[c] Prof. Dr. K. Okada, Prof. Dr. M. Kozaki

Osaka City University Advanced Research Institute for Natural

Science and Technology (OCARINA)

3-3-138, Sugimoto, Sumiyoshi-ku

Osaka 558-8585 (Japan)

E-mail: okadak@sci.osaka-cu.ac.jp

Supporting information for this article is given via a link at the end of the document.
pQDM derivatives with ambipolar (electron and hole) transporting abilities have been described. ${ }^{5}$ These reports demonstrate that quinodimethane systems are promising materials for organic electronics.

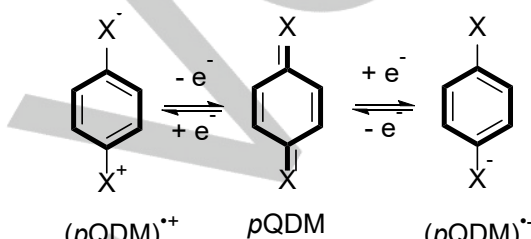

Figure 1. Formation of aromatic rings through redox processes of $p$-quinoidal compounds $\left(\mathrm{X}=\mathrm{O}, \mathrm{NR}, \mathrm{CR}_{2}\right)$

Radical cationic species are known to play an important role as positive-charge carriers in p-type semiconducting layers. Structure and properties of a $p Q D M$-based radical cation should provide novel information about a hole mobility of a $p Q D M-$ based organic semiconductor. The generation and preparation of $p Q D M-b a s e d$ radical cations in solution have been previously reported; ${ }^{6}$ however, to the best of our knowledge, there is no example of their isolation.

In this paper, we investigated syntheses, structures, and properties of a $p Q D M$ system, 2,9-dibromo-7,14-dimesityl-5,12dioxapentacene (1) and its radical cation salt $1^{++} \cdot \mathrm{SbF}_{6}{ }^{-}$. We compared their properties with those of the electron-rich 0 quinodimethane (oQDM) system, 5,8-dioxapentaphene derivatives 2 and $2^{\cdot+} \cdot \mathrm{SbF}_{6}{ }^{-}$, which were studied in our previous paper. ${ }^{7}$ Comparison of fundamental properties between $p Q D M$ and $O Q D M$ in the related system has rarely been reported.<smiles></smiles><smiles></smiles>

\section{Results and Discussion}

Synthesis of 2,9-dibromo-7,14-dimesityl-5,12dioxapentacene

The pentacene-like pQDM system 1 was constructed by a procedure outlined in Scheme 1. The starting 2,5dibromoterephthalic acid, prepared by a reported method, ${ }^{8}$ was 
converted into the corresponding acid chloride $\mathbf{3}$ using thionyl chloride. Next, the Friedel-Crafts reaction of $\mathbf{3}$ with 4bromoanisole was performed using aluminum chloride under heating conditions, and dibenzoylbenzene 4 was obtained in $77 \%$ yield over two steps. The linearly fused framework was constructed by the intramolecular Ullmann-type coupling reaction using picolinic acid as a ligand, which afforded dione $\mathbf{5}$ in $65 \%$ yield. Finally, 5 was treated with mesityl Grignard reagent and then tin(II) chloride to obtain pQDM system 1 as a deep red solid in $40 \%$ yield.<smiles>O=C(O)c1cc(Br)c(C(=O)O)cc1Br</smiles><smiles>O=C(Cl)c1cc(Br)c(C(=O)Cl)cc1Br</smiles>

3<smiles>COc1ccc(Br)cc1</smiles>
$\mathrm{CH}_{2} \mathrm{Cl}_{2}$ $0{ }^{\circ} \mathrm{C}$ to rt, $18 \mathrm{~h} \longrightarrow$ reflux, $6 \mathrm{~h}$ $77 \%$ (in 2 steps)<smiles>O=C(c1cc(Br)ccc1O)c1cc(Br)c(C(=O)c2cc(Br)ccc2O)cc1Br</smiles>

4

both molecules $\mathbf{A}$ and $\mathbf{B}$, clear bond-length alternations around the central ring $C$ were observed (Table 1 ), indicating that 1 is a pQDM homologue. The crystal structure of $\mathbf{1}$ displays a decrease in the extent of bond-length alternations compared to that of oQDM system 2 (Table S2), as evidenced by the calculated HOMA (harmonic oscillator model of aromaticity) index. ${ }^{9}$ The HOMA values of the central ring $C$ were estimated to be -0.202 for 2 and 0.308 (molecule A) and 0.335 (molecule B) for of $\mathbf{1}$. These results suggest that the fused ring system in 1 had a more delocalized $\pi$-conjugation as compared to that in $\mathbf{2}$.

Judging from bond lengths, oQDA 2 has a larger bond-length alternation effect than $p Q D A 1$. In order to obtain insight whether the larger bond-length alternation for $\mathbf{2}$ is due to twisted structure because of the aryl groups or not, we examined the optimization of the structure of the parent compounds 7 and 8 , obtained by DFT calculations at the B3LYP/6-31G** level (Table 2). Both 7 and 8 have planar fused cyclic frameworks in the optimized structures. Relatively small difference in bond lengths was obtained between 7 and 8 . The HOMA value of compound 8 changes to positive although it is still smaller than that of 7 (Table 2). These results suggest that the large differences in the bond-length alternation effect and HOMA values between 1 and $\mathbf{2}$ are mainly due to the twisted structure of $\mathbf{2}$.<smiles>O=c1c2cc(Br)ccc2oc2cc3c(=O)c4cc(Br)ccc4oc3cc12</smiles>

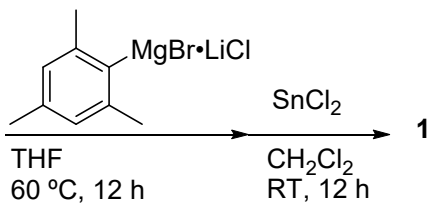

$40 \%$

Scheme 1. Synthetic route of 1.

\section{Molecular structure}

The detailed structure of 1 was determined by X-ray structural analysis (Figure 2 and Table S1). Recrystallization by slow diffusion of acetonitrile into the $\mathrm{CH}_{2} \mathrm{Cl}_{2}$ solution of 1 gave suitable crystals for $\mathrm{X}$-ray analysis. Two crystallographically independent molecules (A and $\mathbf{B}$ ) were observed in the unit cell, each having an inversion center. The dihedral angles of the mesityl groups were almost perpendicular to the backbone $\left(89^{\circ}\right)$. Whereas molecule $\mathbf{B}$ is almost planar $\left(177.10^{\circ}\right.$ between rings $A-$ C), molecule A showed a slightly bent $\pi$-system $\left(174.29^{\circ}\right)$. The differences are a result of packing effects because they were not seen in a DFT-optimized structure (Figure S4). This consideration is further supported by intermolecular $\mathrm{Br} \cdots \mathrm{H}$ (aromatic $\mathrm{H}$ in a mesityl group) interactions $(3.02 \AA)$ shorter than the sum of the van der Waals radii in molecule B (Figure S1). In a)

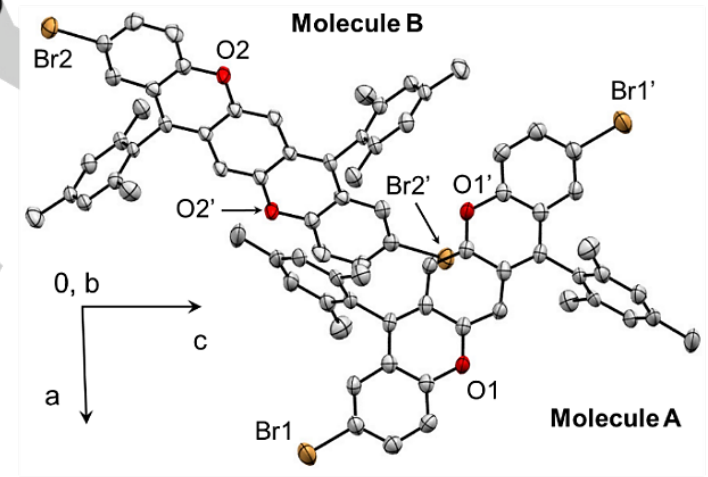

b)

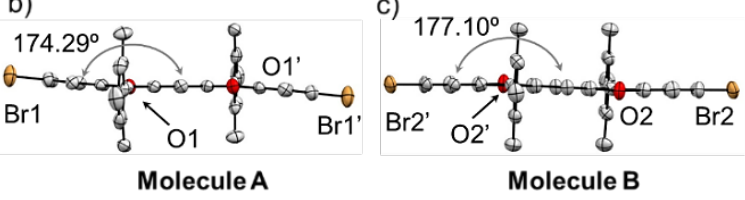

Figure 2. Crystal structures of 1: a) in the unit cell along $b$ axis and b) side views for molecule $\mathbf{A}$ and c) B. Hydrogen atoms are omitted for clarity. Thermal ellipsoids set at $50 \%$. Gray double-headed arrows and values indicate the dihedral angles between rings $A$ and $C$. a)<smiles>C[C@@H]1C2CC(Br)CCC2OC2CC3[C@H](CC21)OC1CCC(Br)CC1[C@@H]3C</smiles>

b)

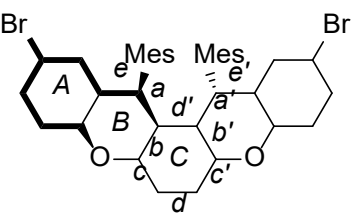

Figure 3. Fused ring systems of a) 1 and b) 2. Italic symbols denote assigned names of the selected bonds and ring positions. 
Table 1. The selected bond lengths ${ }^{[a]}$ and HOMA values of 1 in the crystal state.

\begin{tabular}{ccccccc}
\hline Bonds $^{[\mathrm{b}]}$ & $a$ & $b$ & $c$ & $d$ & $e$ & HOMA $^{[\mathrm{c}]}$ \\
\hline molecule A & $1.366(6)$ & $1.453(4)$ & $1.356(6)$ & $1.441(5)$ & $1.448(5)$ & 0.308 \\
molecule B & $1.376(6)$ & $1.439(6)$ & $1.352(6)$ & $1.450(7)$ & $1.447(7)$ & 0.335 \\
\hline
\end{tabular}

[a] In $\AA$ unit. [b] The crystal structures and assignment of bond names are shown in Figures 2 and 3, respectively. [c] Estimated using the bond lengths of $b, c$, and $d$.

Table 2. Calculated values ${ }^{[a]}$ of the selected bond lengths for 1, 2, 7, and 8 .

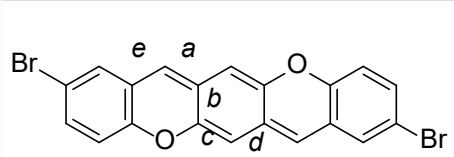

7

\begin{tabular}{ccccccc}
\hline Bonds & $a$ & $b$ & $c$ & $d\left(d^{\prime}\right)$ & $e$ & HOMA $^{[\mathrm{b}]}$ \\
\hline $\mathbf{1}^{[\mathrm{c}]}$ & 1.383 & 1.451 & 1.362 & 1.438 & 1.451 & 0.386 \\
$\mathbf{2}^{[\mathrm{cc}]}$ & 1.378 & 1.467 & 1.353 & $\begin{array}{c}1.439 \\
(1.488)\end{array}$ & 1.476 & -0.183 \\
$\mathbf{7}^{[\mathrm{c}]}$ & 1.373 & 1.453 & 1.361 & 1.437 & 1.436 & 0.368 \\
$\mathbf{8}^{[\mathrm{c}]}$ & 1.370 & 1.451 & 1.358 & $\begin{array}{c}1.433 \\
(1.478)\end{array}$ & 1.439 & 0.147 \\
\hline
\end{tabular}

[a] In $\AA$ unit. [b] for the central ring. [c] All geometries were optimized by DFT calculation at the B3LYP/6-31G** level.

\section{Electronic properties of 1}

The UV-vis absorption spectrum of 1 in $\mathrm{CH}_{2} \mathrm{Cl}_{2}$ exhibited an intense and sharp absorption band $\left(\lambda_{\max }=523 \mathrm{~nm}, \varepsilon_{\max }=1.06 \times\right.$ $10^{5} \mathrm{M}^{-1} \mathrm{~cm}^{-1}$ ) in the $400-550 \mathrm{~nm}$ region with a defined vibrational structure (Figure 4). Form the peak separation values in the absorption band of 1 ( $\lambda_{\text {peak }}=523,487$, and $\left.456 \mathrm{~nm}\right)$, the vibrational energy was estimated to be ca. $1400 \mathrm{~cm}^{-1}$, which can be attributed to stretching vibrations of olefinic and/or aromatic $\mathrm{C}=\mathrm{C}$ bonds $\left(v_{\mathrm{C}=\mathrm{C}}=1400-1600 \mathrm{~cm}^{-1}\right.$ in $\mathrm{S}_{1}$ states). ${ }^{10}$ In addition, 1 produced a sharp fluorescence band in the $500-650 \mathrm{~nm}$ region $\left(\lambda_{\max }=534 \mathrm{~nm}\right)$, which resembles a mirror image of the lowest energy absorption band. These photophysical properties of $\mathbf{1}$ are drastically different from those of oQDM system 2, which showed a structureless broad absorption and no emission (Figure 4$).{ }^{7}$ The small Stokes shift $\left(\Delta v_{0-0}=394 \mathrm{~cm}^{-1}\right)$ for 1 suggests a rigid $\pi$-backbone during the excitation and relaxation processes. In addition, the TD-DFT calculations for 1 revealed that the direction of the transition dipole moment of the $S_{0} \rightarrow S_{1}$ excitation ( $\lambda_{\text {calcd }}=509 \mathrm{~nm}$, Table S3) was parallel to the $\mathrm{C}=\mathrm{C}$ bonds in the $p Q D M$ moiety (Figure $5 \mathrm{e}$ ). These results suggest that the $S_{0} \rightarrow S_{1}$ excitation of 1 can strongly couple with the asymmetric stretching vibrations of the pQDM moiety. On the other hand, the $\pi$-backbone of $\mathbf{2}$ is twisted and flexible due to its flipping motion. In addition, the transition dipole moment of the $\mathrm{S}_{0} \rightarrow \mathrm{S}_{1}$ excitation $\left(\lambda_{\text {calcd }}=642 \mathrm{~nm}\right.$ ) of 2 was orthogonal to the $C_{2}$ axis of the $O Q D M$ skeleton (Figure $5 f$ ). ${ }^{11}$ Presumably, these structural and physical properties of $\mathbf{2}$ are responsible for the structureless broad absorption band and quenching of the radiative relaxation. ${ }^{12}$

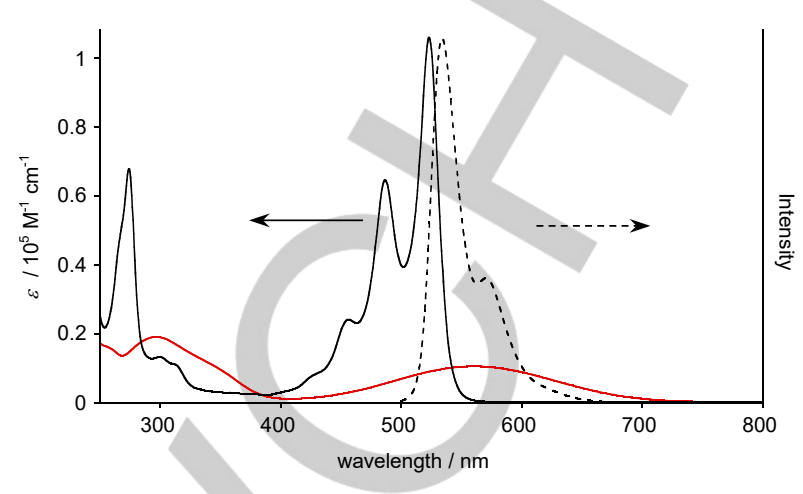

Figure 4. UV-vis absorption (black solid line) and fluorescence (black broken line, $\lambda_{\mathrm{ex}}=487 \mathrm{~nm}$ ) spectra of 1 and UV-vis absorption spectrum of 2 (red solid line) in $\mathrm{CH}_{2} \mathrm{Cl}_{2}$.

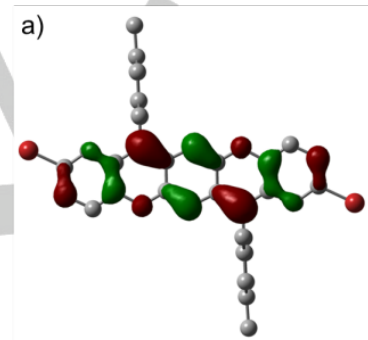

c)

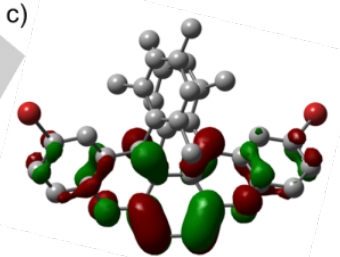

e)

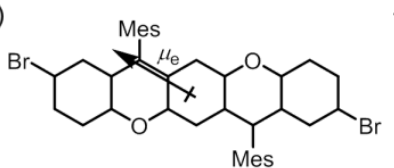

b)

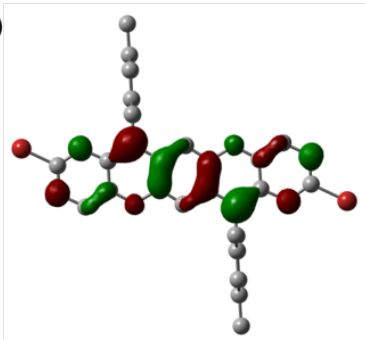

d)
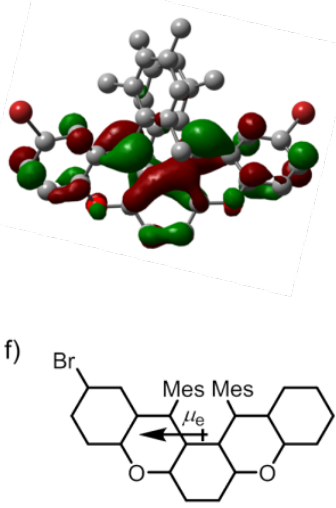

Figure 5. Calculated structures and orbitals a) HOMO and b) LUMO of 1 , and c) HOMO and d) LUMO of 2 (isovalue $=0.035$ ) optimized at the DFT B3LYP/6$31 \mathrm{G}^{* *}$ level. Theoretical transition dipole moments of the $\mathrm{S}_{0} \rightarrow \mathrm{S}_{1}$ excitations of e) 1 and f) 2 were calculated by TD-DFT at the B3LYP/6-31G** level. Hydrogen atoms are omitted for clarity.

The cyclic voltammogram of 1 in $\mathrm{CH}_{2} \mathrm{Cl}_{2}$ (Figure 6) showed two reversible redox waves at $+0.14 \mathrm{~V}$ and $+0.69 \mathrm{~V}\left(\mathrm{vs} \mathrm{Fc}^{+} / \mathrm{Fc}\right)$ and one irreversible redox wave $(-2.13 \mathrm{~V}$ as a peak potential). Thus, the cationic species of 1 are electrochemically stable. In fact, the spectral change of 1 under the application of an external potential of $+0.24 \mathrm{~V}\left(\mathrm{vs} \mathrm{Fc}^{+} / \mathrm{Fc}\right)$ revealed a quantitative generation of the corresponding radical cationic species $1^{\text {1+ }}$ 
(Figure S2). The identification of $\mathbf{1}^{\text {.+ }}$ was supported by a chemical oxidation (vide infra) and spectral assignment was carried out using TD-DFT calculations (Table S4). The reduction potentials for $\mathbf{1}^{+} / \mathbf{1}(+0.14 \mathrm{~V})$ and $\mathbf{1}^{2+} / \mathbf{1}^{+}(+0.69 \mathrm{~V})$ had a higher voltage than the corresponding potentials of $2(+0.07 \mathrm{~V}$ and $+0.42 \mathrm{~V}$, respectively), because of the delocalization of the HOMO of 1 in the planar $\pi$-framework (Figure 5). On the other hand, the gap between the potentials of $1^{+} / 1$ and $1^{2+} / 1^{+}(\Delta E=$ $0.55 \mathrm{~V})$, which is involved by the onsite Coulomb repulsion between the two positive charges, was larger than that of $\mathbf{2}(\Delta E$ $=0.35 \mathrm{~V})$ in spite of the delocalized nature of the HOMO of 1 . These results can be explained by the stability of the dicationic species (Figure 7). After the two-electron oxidation, $\mathbf{1}^{2+}$ has a contribution of the pentacene-like electronic structure 1B, ${ }^{4 e}$ whereas $\mathbf{2}^{2+}$ can form a pentaphene-like electronic structure 2B. According to Clar's aromatic sextet theory, ${ }^{13}$ pentacene has only one sextet ring whereas the pentaphene skeleton has two sextet rings, indicating that the electronic structure of pentaphene is more stable. Thus, the pentaphene-like resonance hybrid stabilizes $\mathbf{2}^{2+}$ and facilitates the second oxidation.

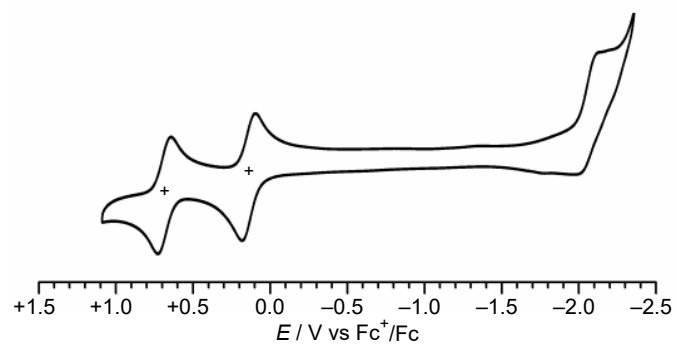

Figure 6. Cyclic voltammogram of 1 in $\mathrm{CH}_{2} \mathrm{Cl}_{2}$ containing $0.1 \mathrm{M} \mathrm{nBu_{4 }} \mathrm{NPF}_{6}$ as a supporting electrolyte at a scan rate of $100 \mathrm{mV} \mathrm{s}^{-1}$<smiles>Cc1c2c(C(C)(C)C)ccc-2oc2ccc(Br)cc12</smiles>

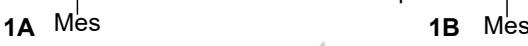

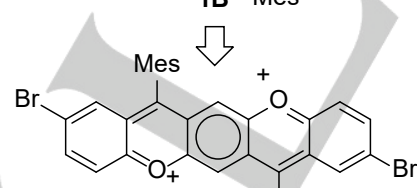

1B Mes

b)

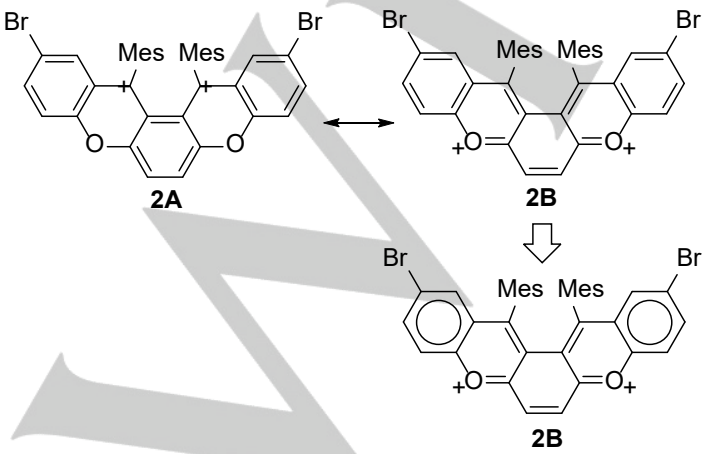

Figure 7. Resonance hybrids of a) $\mathbf{1}^{2+}$ and b) $\mathbf{2}^{2+}$.
DFT calculations of 1 and $\mathbf{2}$ show the localization of both the HOMOs and the LUMOs on the fused-ring systems (Figure 5), indicating insignificant effect of the mesityl groups on the electrochemical and optical properties of the QDM systems due to the large dihedral angles between the mesitiyl units and the fused-ring systems.

\section{Properties and crystal structure of radical cation salt} $1^{\cdot+} \cdot \mathrm{SbF}_{6}^{-}$

The chemical oxidation of $\mathbf{1}$ was carried out using tris(4bromophenyl)aminium hexafluoroantimonate $\left(\mathrm{TBPA} \cdot \mathrm{SbF}_{6}\right)$ as an oxidant (Scheme 2 ), and the desired radical cation salt $\mathbf{1}^{\cdot+} \cdot \mathrm{SbF}_{6}{ }^{-}$ was isolated as a dark red solid in $98 \%$ yield by reprecipitation from the $\mathrm{CH}_{2} \mathrm{Cl}_{2}$ solution using ether. The UV-vis-near infrared (NIR) spectrum of $1^{\cdot+} \cdot \mathrm{SbF}_{6}{ }^{-}$in $\mathrm{CH}_{2} \mathrm{Cl}_{2}$ (Figure 8) is consistent with that observed during the electrochemical oxidation (Figure S2). Moreover, $1^{++} \cdot \mathrm{SbF}_{6}{ }^{-}$showed negligible spectral change after 1 day under aerated conditions at room temperature, indicating the high stability of $\mathbf{1}^{+\cdot} \cdot \mathrm{SbF}_{6}{ }^{-}$(Figure S3). The lowestenergy absorption band in the 700-1000 nm region, which mainly ascribed to the SOMO-LUMO transition (Figure S2 and Table S4), showed a clear vibrational structure $\left(\lambda_{\text {peak }}=958,835\right.$, and $737 \mathrm{~nm}$ ) similar to 1 . The vibrational energies in the $S_{1}$ state were estimated to be 1538 and $1592 \mathrm{~cm}^{-1}$, suggesting that the electronic structure of $\mathbf{1}^{\cdot+} \cdot \mathrm{SbF}_{6}{ }^{-}$has a quasi-pQDM nature. ${ }^{10}$

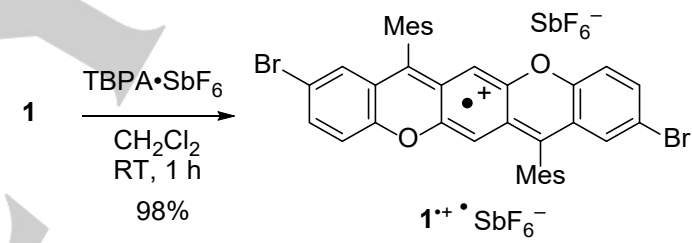

Scheme 2. Synthesis of $1^{\cdot+} \cdot \mathrm{SbF}_{6}{ }^{-}$.

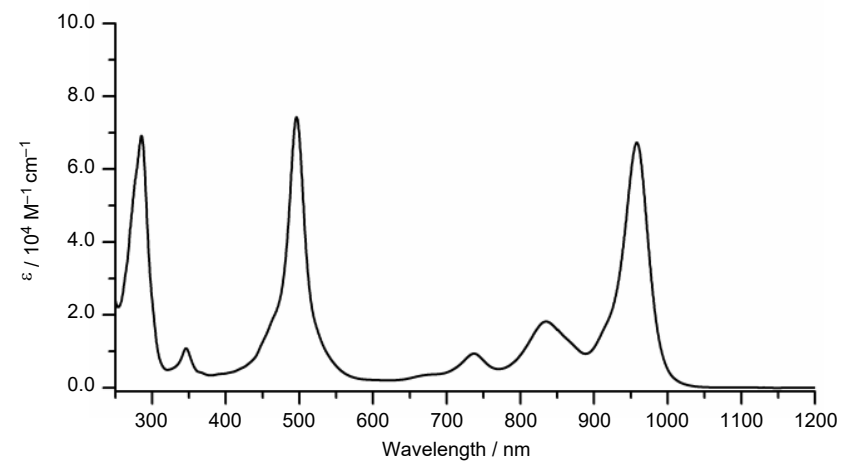

Figure 8. UV-vis-NIR absorption spectrum of $1^{\cdot+} \cdot \mathrm{SbF}_{6}{ }^{-}$in $\mathrm{CH}_{2} \mathrm{Cl}_{2}$.

The electron-spin resonance (ESR) spectrum of $1^{\cdot+\cdot} \cdot \mathrm{SbF}_{6}{ }^{-}$in degassed $\mathrm{CH}_{2} \mathrm{Cl}_{2}$ at room temperature showed multiple split lines with $g=2.0033$ (Figure 9) and is drastically different from that of $O Q D M$ system $2^{\cdot+\cdot} \mathrm{SbF}_{6}{ }^{-}$, in which the spin densities are mainly localized on the central ring. $^{7}$ The observed ESR 
spectrum was reproduced by spectral simulation with the following hyperfine coupling constants for the four sets of ${ }^{1} \mathrm{H}$ nuclei $(I=1 / 2):\left|a^{1 \mathrm{H}}\right|(\times 2)=2.49 \times 10^{-4} \mathrm{~cm}^{-1}(0.266 \mathrm{mT}),\left|\mathrm{a}^{1 \mathrm{H}}\right|$ $(\times 2)=2.10 \times 10^{-4} \mathrm{~cm}^{-1}(0.225 \mathrm{mT}),\left|a^{1 \mathrm{H}}\right|(\times 2)=1.22 \times 10^{-4} \mathrm{~cm}^{-1}$ $(0.131 \mathrm{mT})$, and $\left|\mathrm{a}^{1 \mathrm{H}}\right|(\times 4)=4.30 \times 10^{-5} \mathrm{~cm}^{-1}(0.046 \mathrm{mT}) .{ }^{14}$ With the aid of the theoretical calculations of $1^{++}$, the former three can be assigned to the two equivalent ${ }^{1} \mathrm{H}$ nuclei at the $6,13-, 3,10-$, and 1,8-positions in the 5,12-dioxapentacene moiety, respectively (Figure 10). The remaining four ${ }^{1} \mathrm{H}$ nuclei can be attributed to one equivalent ${ }^{1} \mathrm{H}$ nuclei in the four o-methyl groups of the mesityl moieties, because of the hindered rotation of the mesityl methyl groups in the ESR time scale. These results indicate that the electron spin of $p Q D M$ system $1^{\cdot+}$ is delocalized over the entire $\pi$-conjugated system whereas in $2^{\cdot+}$ the spin density is localized on the oQDM moiety. ${ }^{7}$

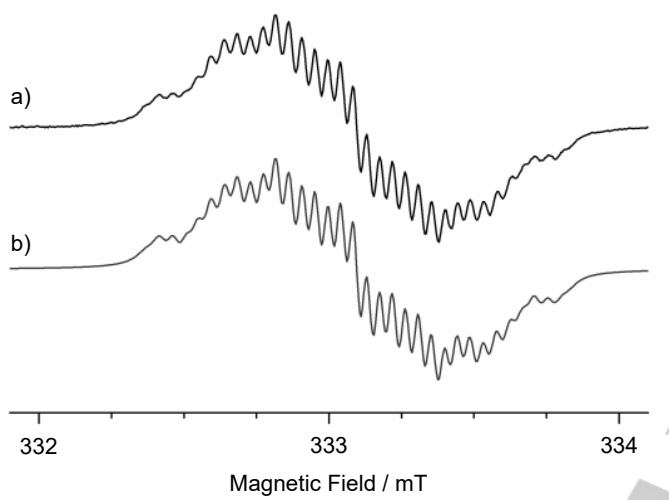

Figure 9. a) Observed and b) simulated ESR spectra of $1^{\cdot+} \cdot \mathrm{SbF}_{6}{ }^{-}$in $\mathrm{CH}_{2} \mathrm{Cl}_{2}$ at room temperature. Parameters for simulation: $g=2.0033,\left|a^{1 \mathrm{H}}\right|(\times 2)=2.49 \times$ $10^{-4} \mathrm{~cm}^{-1}(0.266 \mathrm{mT}),\left|a^{1 \mathrm{H}}\right|(\times 2)=2.10 \times 10^{-4} \mathrm{~cm}^{-1}(0.225 \mathrm{mT}),\left|a^{1 \mathrm{H}}\right|(\times 2)=1.22$ $\times 10^{-4} \mathrm{~cm}^{-1}(0.131 \mathrm{mT})$, and $\left|a^{1 \mathrm{H}}\right|(\times 4)=4.30 \times 10^{-5} \mathrm{~cm}^{-1}(0.046 \mathrm{mT})$.

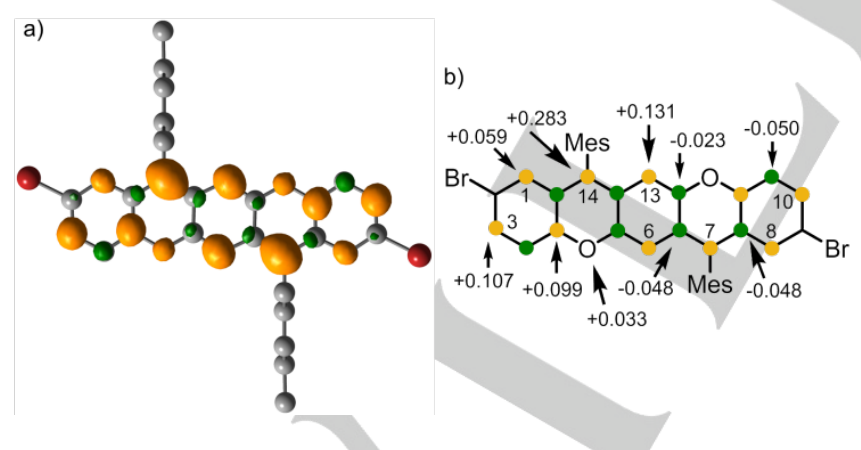

Figure 10. a) Spin density map (isovalue $=0.002$, yellow positive spin, green negative spin) and b) spin density values of $1^{\text {.+ }}$ optimized at the DFT UB3LYP/6-31G** level. Hydrogen atoms are omitted for clarity.

Moreover, the X-ray structural analysis of $1^{\cdot+\cdot} \cdot \mathrm{SbF}_{6}{ }^{-}$was successfully performed (Figure 11 and Table S1). Recrystallization by slow diffusion of ether into the $\mathrm{CH}_{2} \mathrm{Cl}_{2}$ solution of $1^{++} \cdot \mathrm{SbF}_{6}{ }^{-}$gave suitable crystals for $\mathrm{X}$-ray analysis, in which the observed $1^{\cdot+\cdot} \cdot \mathrm{SbF}_{6}{ }^{-}$contained two $\mathrm{CH}_{2} \mathrm{Cl}_{2}$ molecules as crystal solvent. The crystal structure of $1^{\cdot+\cdot} \cdot \mathrm{SbF}_{6}{ }^{-}$has an inversion center and a form similar to that of the corresponding neutral species, i.e., a slightly bent $\left(175.48^{\circ}\right) \pi$-framework and $87^{\circ}$-twisting mesityl groups. Reduced bond-length alternations around the central ring $C$ were observed (Table 3 ), which is consistent with the NIR absorption band with the well-resolved vibrational structure. The bond lengths $e, b$, and $d$ of $1^{\cdot+}$ are shorter than the neutral molecule, which reflects the antibonding character of these bonds in HOMO of the neutral molecule (Figure 5a). The HOMA value of the central ring $C$ was estimated to be 0.668 , clearly indicating delocalization of the $\pi$ conjugated system of $\mathbf{1}^{\cdot+}$ and thus confirming the results of the ESR study.

a)

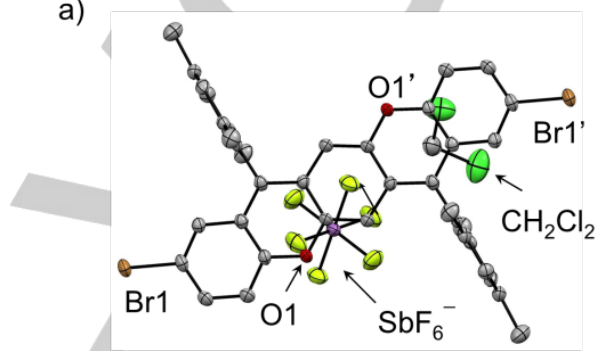

b)

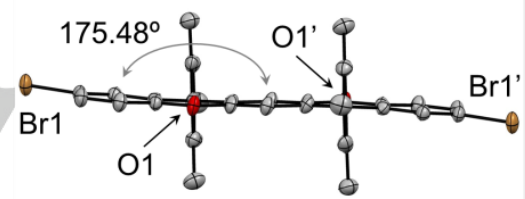

Figure 11. Crystal structures of $1^{{ }^{+} \cdot \mathrm{SbF}_{6}}{ }^{-}:$a) Top view and b) side view along short axis of $1^{++}$. Hydrogen atoms are omitted for clarity. Thermal ellipsoids set at $50 \%$. In b), the counter anion and crystal solvents are omitted for clarity. The gray double-headed arrow and the value indicate the dihedral angle between rings $A$ and $C$ (Figure 3)

Table 3. The selected bond lengths ${ }^{[a]}$ and $\mathrm{HOMA}$ values of $\mathbf{1}^{++} \cdot \mathrm{SbF}_{6}{ }^{-}$

\begin{tabular}{ccccccc}
\hline Bonds $^{[b]}$ & $a$ & $b$ & $c$ & $d$ & $e$ & HOMA $^{[c]}$ \\
\hline $\mathbf{1}^{\boldsymbol{H}^{+} \cdot \mathrm{SbF}_{6}^{-}}$ & $1.386(4)$ & $1.432(4)$ & $1.358(4)$ & $1.420(4)$ & $1.414(4)$ & 0.668 \\
\hline
\end{tabular}

[a] In $\AA$ unit. [b] Assignment of bond names are shown in Figure 3. [c] Estimated using the bond lengths of $b, c$, and $d$.

\section{Conclusions}

An electron-rich pQDM system, 2,9-dibromo-7,14-dimesityl-5,12dioxapentacene, was prepared and its structure and properties were compared to the isomeric oQDM system. Single crystal $X-$ ray analysis revealed smaller bond-length alternation in the pQDM system than that in the twisted oQDM system. While the oQDM system showed broad absorption bands and no fluorescence, the absorption and fluorescence bands with wellresolved vibrational structures were observed for the $p Q D M$ system. Additionally, the radical cationic species of the $p Q D M$ 
system was prepared by the chemical oxidation and successfully isolated. The ESR spectrum of the $p Q D M$ radical cation exhibited the well delocalized spin density pattern, although the much simpler localized pattern was observed for the oQDM radical cation. These results make a sharp contrast between the $o$ QDM and $p Q D M$ systems and provide useful guidelines for material applications.

\section{Experimental Section}

\section{Methods}

Melting points were taken on a Yanaco MP J-3 and were uncorrected. ${ }^{1} \mathrm{H}$ and ${ }^{13} \mathrm{C}$ NMR spectra were recorded on a Bruker Avance III 400 spectrometer. Chemical shifts were reported in parts per million downfield for tetramethylsilane as an internal (for $\mathrm{CDCl}_{3}$ ) and an external (for sulfuric acid- $d_{2}$, using the value in $\mathrm{CDCl}_{3}$ ) standard or relative to solvent signal $\left(\mathrm{CHCl}_{3}: \delta=7.26\right.$ for ${ }^{1} \mathrm{H} \mathrm{NMR}$ and $\delta=77.0 \mathrm{ppm}$ for ${ }^{13} \mathrm{C}$ NMR) as internal standards, and all coupling constants are reported in $\mathrm{Hz}$ (Multiplicity: $\mathrm{s}=$ singlet; $\mathrm{d}=$ doublet). ESR spectrum of $1^{{ }^{+} \cdot \mathrm{SbF}_{6}{ }^{-} \text {was }}$ recorded on a Bruker ELEXSYS E500 spectrometer. IR spectra were recorded on a JASCO FT/IR-4600 spectrometer. DART-TOF and ESITOF mass spectra were recorded on a JEOL AccuTOF LC-plus JMST100LP spectrometer. Elemental analyses were obtained from the Analytical Centre in Osaka City University, using a Fisons EA1108 and a J-Science JM10. X-ray data were collected by a Rigaku Saturn 724 CCD system with graphite monochromated Mo- $K_{\alpha}$ radiation. Absorption spectra were recorded on a Shimadzu UV-2550 spectrometer and a JASCO V670 spectrometer. Merck Silica gel 60 (63-200 mesh) or Kanto Chemical Silica gel 60 (100-200 mesh) were used for column chromatography. The progress of reactions was monitored using thinlayer chromatography using Merck TLC silica gel $60 \mathrm{~F}_{254}$. All commercially available compounds were reagent grade and used without further purification. Dehydrate DMSO was purchased. THF was dried and distilled over sodium. $\mathrm{CH}_{2} \mathrm{Cl}_{2}$ was dried and distilled over calcium hydride. 2,5-Dibromoterephthalic acid was prepared by the reported method. ${ }^{8}$

\section{1,4-Dibromo-2,5-di(5-bromo-2-hydroxybenzoyl)benzene (4)}

2,5-Dibromoterephthalic acid $(4.56 \mathrm{~g}, 15.0 \mathrm{mmol})$ and one drop of DMF were placed in a $300 \mathrm{~mL}$ two-necked round bottom flask with thionyl chloride $(65 \mathrm{~mL})$. The suspension was refluxed at $90^{\circ} \mathrm{C}$ for $1 \mathrm{~h}$ under a $\mathrm{N}_{2}$ atmosphere. After cooling to RT, an excess amount of thionyl chloride was removed under reduced pressure to obtain the corresponding acid chloride 3 as a pale-brown crude solid. This crude compound was used in the next step without further purification.

After refilling the reaction equipment with $\mathrm{N}_{2}$, the obtained crude 3 was dissolved in $\mathrm{CH}_{2} \mathrm{Cl}_{2}(100 \mathrm{~mL})$, and the mixture was cooled at $0{ }^{\circ} \mathrm{C}$. To this solution was added finely-grounded $\mathrm{AICl}_{3}$ by a portion. The resulting mixture was stirred at $0{ }^{\circ} \mathrm{C}$ for $30 \mathrm{~min}$ and then warmed up to RT. After stirring for $30 \mathrm{~min}$ at $\mathrm{RT}$, the mixture was cooled again to $0^{\circ} \mathrm{C}$, and then a solution of 4-bromoanisole $(11.2 \mathrm{~g}, 60.0 \mathrm{mmol})$ in $\mathrm{CH}_{2} \mathrm{Cl}_{2}(50 \mathrm{~mL})$ was added slowly. The resulting mixture was allowed to warm up to RT. After stirring for $18 \mathrm{~h}$ at $\mathrm{RT}$, the mixture was refluxed at $90^{\circ} \mathrm{C}$ for additional $6 \mathrm{~h}$ After cooling to RT, the mixture was poured in to an excess amount of 4 $\mathrm{M}$ aq $\mathrm{HCl}$ cooled at $0{ }^{\circ} \mathrm{C}$. The resulting precipitate was collected by filtration, and the residue was washed with water and $\mathrm{EtOH}$ to obtain 4 (7.34 g, $77 \%)$ as a pale yellow powder. m.p. $276-277{ }^{\circ} \mathrm{C} ;{ }^{1} \mathrm{H}$ NMR $(400$ $\left.\mathrm{MHz}, \mathrm{CDCl}_{3}\right): \delta=11.63(\mathrm{~s}, 2 \mathrm{H}), 7.66(\mathrm{dd}, J=8.9$ and $2.4 \mathrm{~Hz}, 2 \mathrm{H}), 7.63(\mathrm{~s}$ 2H), $7.35(\mathrm{~d}, J=2.4 \mathrm{~Hz}, 2 \mathrm{H}), 7.03 \mathrm{ppm}(\mathrm{d}, J=8.9 \mathrm{~Hz}, 2 \mathrm{H}) ;{ }^{13} \mathrm{C}$ NMR $\left(100 \mathrm{MHz}, \mathrm{CDCl}_{3}\right): \delta=197.6,162.4,141.6,140.8,134.8,132.8,120.9$, 119.7, 118.5, $111.2 \mathrm{ppm}$; IR (KBr) $v_{\max }=3147(\mathrm{br}), 3086,1762,1735$, 1678, 1630, 1607, 1568, 1463, 1348, 1285, 1231, 1207, 1154, 1065, 945, 893, 827, 733, 645, $521 \mathrm{~cm}^{-1}$; MS (DART-TOF-): $\mathrm{m} / \mathrm{z}: 630.9,632.9$, $634.9\left[\mathrm{M}-\mathrm{H}^{-}\right]$; elemental analysis calcd $(\%)$ for $\mathrm{C}_{20} \mathrm{H}_{10} \mathrm{Br}_{4} \mathrm{O}_{4}: \mathrm{C} 37.89, \mathrm{H}$ 1.59; found: C 38.16 ; H 1.63 .

\section{2,9-Dibromo-7,14-dihydro-5,12-dioxapentacene-7,14-dione (5)}

Picolinic acid (118 mg, $0.96 \mathrm{mmol}$ ), Cul (91 mg, $0.48 \mathrm{mmol}$ ), and $\mathrm{K}_{3} \mathrm{PO}_{4}$ $(1.36 \mathrm{~g}, 6.41 \mathrm{mmol})$ were placed in a $50 \mathrm{~mL}$ two-neck round bottom flask with DMSO $(16 \mathrm{~mL})$. The mixture was degassed by a $\mathrm{N}_{2}$-bubbling for 5 min and heated at $50{ }^{\circ} \mathrm{C}$ for $30 \mathrm{~min}$. To this suspension after cooling to RT, $4(1.01 \mathrm{~g}, 1.60 \mathrm{mmol})$ was added using DMSO $(8 \mathrm{~mL})$ as a rinse solvent. The mixture was heated at $120{ }^{\circ} \mathrm{C}$ for $24 \mathrm{~h}$ under a $\mathrm{N}_{2}$ atmosphere. After cooling to RT, the mixture was poured in to an excess amount of $4 \mathrm{M} \mathrm{aq} \mathrm{HCl}$. The resulting precipitate was collected by filtration, and the residue was washed with $\mathrm{EtOH}$. The obtained crude product was completely dissolved in $18 \mathrm{M} \mathrm{H}_{2} \mathrm{SO}_{4}$, and then the deep-red solution was added dropwise into ice-cooled water. The generated precipitate was collected by filtration, and the residue was washed with water and $\mathrm{EtOH}$ to obtain $5(490 \mathrm{mg}, 65 \%)$ as a brownish yellow powder. m.p. $>300{ }^{\circ} \mathrm{C}$; ${ }^{1} \mathrm{H}$ NMR $\left(400 \mathrm{MHz}, \mathrm{D}_{2} \mathrm{SO}_{4}\right): \delta=8.65(\mathrm{~s}, 2 \mathrm{H}), 8.11(\mathrm{~d}, J=1.8 \mathrm{~Hz}, 2 \mathrm{H})$, 7.81 (dd, $J=9.3$ and $1.8 \mathrm{~Hz}, 2 \mathrm{H}), 7.35 \mathrm{ppm}(\mathrm{d}, J=9.3 \mathrm{~Hz}, 2 \mathrm{H}) ;{ }^{13} \mathrm{C} \mathrm{NMR}$ $\left(100 \mathrm{MHz}, \mathrm{D}_{2} \mathrm{SO}_{4}\right): \delta=177.5,159.7,150.9,149.2,127.5,122.7,121.4$, 121.0, 118.1, $114.7 \mathrm{ppm}$; IR (KBr) $v_{\max }=3086,1664,1602,1463,1447$ 1339, 1269, 1205, 1127, 913, 823, 787, 662, 531, $418 \mathrm{~cm}^{-1}$; MS (DARTTOF $^{+}$): $m / z: 471.0,472.0,474.0\left[M+\mathrm{H}^{+}\right]$; elemental analysis calcd (\%) for $\mathrm{C}_{20} \mathrm{H}_{8} \mathrm{Br}_{2} \mathrm{O}_{4}$ : C 50.88, H 1.71; found: C 50.72, H 1.84 .

\section{2,9-Dibromo-7,14-dimesityl-5,12-dioxapentacene (1)}

To prepare mesityl Grignard reagent, in a $10 \mathrm{~mL}$ two-necked round bottom flask under a $\mathrm{N}_{2}$ atmosphere, the solution of 2-bromomesitylene $(1.19 \mathrm{~g}, 6.00 \mathrm{mmol})$ in THF $(3 \mathrm{~mL})$ was added slowly to the suspension of anhydrous $\mathrm{LiCl}(212 \mathrm{mg}, 5.00 \mathrm{mmol})$ and $\mathrm{Mg}$ turnings $(120 \mathrm{mg}, 5.00$ $\mathrm{mmol})$ in THF $(3 \mathrm{~mL})$ at $40{ }^{\circ} \mathrm{C}$, and the mixture was stirred for $1 \mathrm{~h}$.

In another $30 \mathrm{~mL}$ two-necked round bottom flask under a $\mathrm{N}_{2}$ atmosphere, $5(472 \mathrm{mg}, 1.00 \mathrm{mmol})$ was placed with THF $(10 \mathrm{~mL})$ at $60{ }^{\circ} \mathrm{C}$. To the suspension of $\mathbf{5}$ was added dropwise slowly the prepared mesityl Grignard reagent, and then the mixture was stirred for $12 \mathrm{~h}$. After cooling to $\mathrm{RT}, 4 \mathrm{M}$ aq $\mathrm{HCl}$ was added to quench the reaction. The aqueous layer was extracted with $\mathrm{CH}_{2} \mathrm{Cl}_{2}$, and the combined organic layer was dried over $\mathrm{Na}_{2} \mathrm{SO}_{4}$. A removal of the solvent under reduced pressure gave the crude mesitylated diol.

The obtained crude diol was dissolved in $\mathrm{CH}_{2} \mathrm{Cl}_{2}(60 \mathrm{~mL})$, and the mixture was degassed by a $\mathrm{N}_{2}$-bubbling for $5 \mathrm{~min}$. After the degassing one drop of $4 \mathrm{M}$ aq $\mathrm{HCl}$ and anhydrous $\mathrm{SnCl}_{2}(1.14 \mathrm{~g}, 6.00 \mathrm{mmol})$ was added, and then the mixture was stirred at RT for $12 \mathrm{~h}$. The resulting mixture was passed through Celite ${ }^{\circledR}$ to remove the excess amount of $\mathrm{SnCl}_{2}$, and then the filtrate was concentrated under reduced pressure. The residue was purified by silica gel column chromatography using $n$ hexane- $\mathrm{CH}_{2} \mathrm{Cl}_{2}(1: 1 \mathrm{v} / \mathrm{v})$ as an eluent, and then the obtained product was washed with $\mathrm{EtOH}$ to obtain $1(274 \mathrm{mg}, 40 \%)$ as a deep red solid. Single crystals of 1 suitable for $\mathrm{X}$-ray analysis were obtained by a liquid diffusion of $\mathrm{CH}_{3} \mathrm{CN}$ with a solution of 1 in $\mathrm{CH}_{2} \mathrm{Cl}_{2}$. m.p. $255^{\circ} \mathrm{C}$ (decomp); ${ }^{1} \mathrm{H}$ NMR $\left(400 \mathrm{MHz}, \mathrm{CDCl}_{3}\right.$ ): $\delta=7.06$ (dd, $J=8.6$ and $2.3 \mathrm{~Hz}, 2 \mathrm{H}$ ), 7.00 (s, $4 \mathrm{H}$ ), $6.63(\mathrm{~d}, J=8.6 \mathrm{~Hz}, 2 \mathrm{H}), 6.48(\mathrm{~d}, J=2.3 \mathrm{~Hz}, 2 \mathrm{H}), 5.41(\mathrm{~s}, 2 \mathrm{H}), 2.08(\mathrm{~s}$, $12 \mathrm{H}), 1.86 \mathrm{ppm}(\mathrm{s}, 6 \mathrm{H}) ;{ }^{13} \mathrm{C}$ NMR $\left(100 \mathrm{MHz}, \mathrm{CDCl}_{3}\right): \delta=152.2,150.8$ $137.9,137.0,130.5,129.8,128.7,128.1,126.0,125.8,124.6,116.5$, 116.3, 100.0, 21.2, $19.7 \mathrm{ppm}$; IR $(\mathrm{KBr}) v_{\max }=2969,2916,2855,1577$, 
1555, 1468, 1407, 1377, 1302, 1260, 1212, 1190, 1165, 1072, 966, 914 849, 808, 761, 664, $581 \mathrm{~cm}^{-1}$; MS (DART-TOF $): \mathrm{m} / \mathrm{z}: 677.2,679.2$, $681.2\left[\mathrm{M}+\mathrm{H}^{+}\right]$; elemental analysis calcd (\%) for $\mathrm{C}_{38} \mathrm{H}_{30} \mathrm{Br}_{2} \mathrm{O}_{2}: \mathrm{C} 67.27, \mathrm{H}$ 4.46; found: C $67.50, \mathrm{H}, 4.66$.

\section{Radical cation hexafluoroantimonate salt $1^{\cdot+} \cdot \mathrm{SbF}_{6}^{-}$}

In a glove box filled with argon, $1(21.4 \mathrm{mg}, 0.0315 \mathrm{mmol})$ was dissolved in $\mathrm{CH}_{2} \mathrm{Cl}_{2}(3 \mathrm{~mL})$. To this solution was added a solution of tris(4bromophenyl)aminium hexafluoroantimonate (TBPA.SbF $6,22.0 \mathrm{mg}$, $0.0307 \mathrm{mmol}$ ) in $\mathrm{CH}_{2} \mathrm{Cl}_{2}$ at $\mathrm{RT}$, and the mixture was stirred for $1 \mathrm{~h}$. The resulting mixture was evaporated under reduced pressure. The residue was dissolved in a minimum amount of $\mathrm{CH}_{2} \mathrm{Cl}_{2}$, and then ether was added slowly. The generated precipitate was collected by filtration to obtain $1^{++} \cdot \mathrm{SbF}_{6}{ }^{-}\left(28.8 \mathrm{mg}\right.$ obtained as $\left.\boldsymbol{1}^{++} \cdot \mathrm{SbF}_{6}{ }^{-} \cdot\left(\mathrm{CH}_{2} \mathrm{Cl}_{2}\right)_{0.2}, 98 \%\right)$ as a dark-red solid. m.p. $250{ }^{\circ} \mathrm{C}$ (decomp); $\mathrm{IR}(\mathrm{KBr}) v_{\max }=3082,2973,2919$, 2859, 1609, 1553, 1482, 1434, 1390, 1333, 1275, 1173, 1139, 1067, 970 918, 822, 766, 660, 580, $547 \mathrm{~cm}^{-1}$; MS (ESI-TOF $\left.{ }^{+}\right): \mathrm{m} / \mathrm{z}: 676.1,678.1$, and $680.1\left[\mathrm{C}_{38} \mathrm{H}_{30} \mathrm{Br}_{2} \mathrm{O}_{2}^{+}\right], \quad\left(\mathrm{ESI}^{-} \mathrm{TOF}^{-}\right) \quad \mathrm{m} / \mathrm{z}: \quad 234.9,236.9 \quad\left[\mathrm{SbF}_{6}{ }^{-}\right.$]; Elemental analysis calcd (\%) for $\left(\mathrm{C}_{38} \mathrm{H}_{30} \mathrm{Br}_{2} \mathrm{O}_{2} \cdot \mathrm{SbF}_{6}\right) \cdot\left(\mathrm{CH}_{2} \mathrm{Cl}_{2}\right)_{0.2:}$ C 49.27 H 3.29; found: C 49.11, H 3.51 .

\section{Electrochemical measurements}

Redox potential was measured using an ALS Electrochemical analyser MODEL 610A in a conventional three-electrode cell equipped with a glassy carbon as a working electrode and a platinum wire as a counter electrode with a SCE reference electrode. The measurement was carried out at a scan rate $100 \mathrm{mV} \mathrm{s}^{-1}$ in $\mathrm{CH}_{2} \mathrm{Cl}_{2}$ containing $0.1 \mathrm{M}$ tetra- $n$ butylammonium hexafluorophosphate as a supporting electrolyte. The redox potentials were finally corrected by the ferrocenium/ferrocene $\left(\mathrm{Fc}^{+} / \mathrm{Fc}\right)$ couple. Absorption spectra of the oxidation species for 1 were recorded on an Ocean Optics HR4000 spectrometer using a $1 \mathrm{~mm}$ width cell equipped with a fine mesh platinum as a working electrode, a platinum wire as a counter electrode, and a SCE reference electrode. The external potential was applied using a Bi-Potentiostat ALS/DY2323 for the electrochemical oxidation of 1 in $\mathrm{CH}_{2} \mathrm{Cl}_{2}$ containing $0.1 \mathrm{M}$ tetra- $n$ butylammonium hexafluorophosphate.

\section{Acknowledgements}

This work was partially supported by Grant-in-Aid for Scientific Research from JSPS KAKENHI (No. JP17K05790 for M.K. and K.O. and No. JP26288041 and No. JP15H00956 for K.O.) and financial support Grant-in-Aid for Scientific Research on Innovative Areas " $\pi-S y s t e m$ Figuration: Control of Electron and Structural Dynamism for Innovative Functions" from MEXT (No. 26102005 to S.S.). C.S. thanks the financial support by the Sasakawa Scientific Research Grant from The Japan Science Society.

Keywords: EPR spectroscopy • Fused-ring systems • Quinodimethanes • Radical ions • Solid-state structures

[1] a) M. Abe, Chem. Rev. 2013, 113, 7011-7088; b) S. Patai, The Chemistry of the Quinonoid Compounds, Wiley, Chichester, 1974; c) S. Patai, Z. Rappoport, The Chemistry of the Quinonoid Compounds, Wiley, Chichester, 1988; Vol. 2. d) Z. Sun, Q. Ye, C. Chi, J. Wu, Chem. Soc. Rev. 2012, 41, 7857-7889.
[2] a) A. Kikuchi, F. Iwahori, J. Abe, J. Am. Chem. Soc. 2004, 126 6526-6527; b) C. J. Tonzola, J. M. Hancock, A. Babel, S. A. Jenekhe Chem. Commun. 2005, 5214-5216; c) X. Zhu, H. Tsuji, K. Nakabayashi, S. Ohkoshi, E. Nakamura, J. Am. Chem. Soc. 2011, 133, 16342-16345; d) M. Kozaki, A. Isoyama, K. Okada, Tetrahedron Lett. 2006, 47, 5375-5378; e) R. P. Ortiz, A. Facchetti, T. J. Marks, J Casado, M. Z. Zgierski, M. Kozaki, V. Hernández, J. T. L. Navarrete, Adv. Func. Mater. 2009, 19, 386-394; f) S. Suzuki, A. Nagata, M Kuratsu, M. Kozaki, D. Shiomi, K. Sato, T. Takui, K. Okada, Angew. Chem. Int. Ed. 2012, 51, 3193-3197; Angew. Chem. 2012, 124, $3247-$ 3251.

[3] a) N. Martin, J. L. Segura, C. Seoane, J. Mater. Chem. 1997, 7, 1661-1676; b) S. Hünig, E. Herberth, Chem. Rev. 2004, 104, 5535-5563; c) G. Saito, Y. Yoshida, Bull. Chem. Soc. Jpn. 2007, 80, 1-137; d) T. Mori, N. Yanai, I. Osaka, K. Takimiya, Org. Lett. 2014, 16, 1334-1337; e) M. Kozaki, K. Sugimura, H. Ohnishi, K. Okada, Org. Lett. 2006, 8, 5235-5238.

[4] a) W. L. Kalb, A. F. Stassen, B. Batlogg, U. Berens, B. Schmidhalter, F. Bienewald, A. Hafner, T. Wagner, J. Appl. Phys. 2009, 105, 043705; b) X. Yang, D. Liu, Q. Miao, Angew. Chem. Int. Ed. 2014, 53, 6786-6790; Angew. Chem. 2014, 126, 6904-6908; c) Q. Ye, J. Chang, X. Shi, G. Dai, W. Zhang, K. -W. Huang, C. Chi, Org. Lett. 2014, 16, 3966-3969; d) K. Sbargoud, M. Mamada, J. Marrot, S. Tokito, A. Yassar, M. Frigoli, Chem. Sci. 2015, 6, 3402-3409; e) X. Yang, X. Shi, N. Aratani, T. P. Gonçalves, K. -W. Huang, H. Yamada, C. Chi, Q. Miao, Chem. Sci. 2016, 7, 6176-6181; f) J. L. Marshall, K. Uchida, C. K. Frederickson, C. Schütt, A. M. Zeidell, K. P. Goetz, T. W. Finn, K. Jarolimek, L. N Zakharov, C. Risko, R. Herges, O. D. Jurchescu, M. M. Haley, Chem. Sci. 2016, 7, 5547-5558

[5] a) J. Nishida, S. Tsukaguchi, Y. Yamashita, Chem. - Eur. J. 2012, 18, 8964-8970; b) D. T. Chase, A. G. Fix, S. J. Kang, B. D. Rose, C. D. Weber, Y. Zhong, L. N. Zakharov, M. C. Lonergan, C. Nuckolls, M. M. Haley, J. Am. Chem. Soc. 2012, 134, 10349-10352; c) G. E Rudebusch, J. L. Zafra, K. Jorner, K. Fukuda, J. L. Marshall, I. Arrechea-Marcos, G. L. Espejo, R. P.Ortiz, C. J.Gómez-García, L. N.Zakharov, M. Nakano, H. Ottosson, J. Casado, M. M. Haley, Nat. Chem. 2016, 8, 753-759.

[6] a) Y. Ueno, A. Nakayama, M. Okawara, J. Chem. Soc., Chem. Commun. 1978, 74-75; b) M. R. Bryce, J. Chem. Soc., Perkin Trans. 1 1985, 1675-1679; c) Y. Yamashita, Y. Kobayashi, T. Miyashi, Angew. Chem. Int. Ed. Engl. 1989, 28, 1052-1053; Angew. Chem. 1989, 101 1090-1091; d) K. Ohashi, T. Kubo, T. Masui, K. Yamamoto, K Nakasuji, T. Takui, Y. Kai, I. Murata, J. Am. Chem. Soc. 1998, 120, 2018-2027.

[7] C. Sato, S. Suzuki, M. Kozaki, K. Okada, Org. Lett. 2016, 18, 1052 1055.

[8] Y. Yao, J. M. Tour, Macromolecules 1999, 32, 2455-2461.

[9] a) T. M. Krygowski, M. Cyrański, Tetrahedron 1996, 52, 1713-1722; b) R. Gleiter, G. Haberhauer, R. Hoffmann, Aromaticity and Other Conjugation Effects; Wiley-VCH: Weinheim, 2012; c) T. M. Krygowski, H. Szatylowicz, O. A. Stasyuk, J. Dominikowska, M. Palusiak, Chem. Rev. 2014, 114, 6383-6422.

[10] a) J. P. Kraack, T. Buckup, M. Motzkus J. Phys. Chem. Lett. 2013, 4, 383-387; b) R. Rossetti, S. M. Beck, L. E. Brus J. Phys. Chem. 1983 87, 3058-3061; c) H.-L. Sheu, S. Kim, J. Laane J. Phys. Chem. A 2013, 117, 13596-13604.

[11] a) C. R. Flynn, J. Michl, J. Am. Chem. Soc. 1974, 96, 3280-3288; b) E. Migirdicyan, J. Baudet, J. Am. Chem. Soc. 1975, 97, 7400-7404.

[12] a) N. I. Nijegorodov, W. S. Downey, J. Phys. Chem. 1994, 98, 5639-5643; b) A. Bedi, L. J. W. Shimon, O. Grdron J. Am. Chem. Soc 2018, 140, 8086-8090.

[13] a) G. Portella, J. Poater, M. Solà, J. Phys. Org. Chem. 2005, 18, 785791; b) Solà M. Front. Chem. 2013, 1:22.

[14] ESR spectral simulation was carried out with WINEPR Simfonia. 
Entry for the Table of Contents (Please choose one layout)

Layout 2:

\section{FULL PAPER}<smiles>CS(=O)(=O)c1cc2c(Oc3ccc(Br)cc3-c3ccccc3)cc1-c1cc(Br)ccc1O2</smiles>

p-quinodimethane

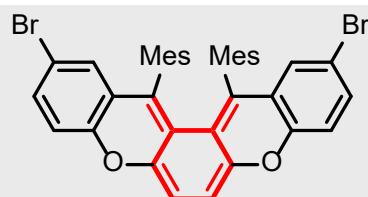

o-quinodimethane

An electron-rich p-quinodimethane system, 2,9-dibromo-7,14-dimesityl-5,12dioxapentacene, was prepared and oxidized to form a stable radical cation. Molecular structure, photophysical properties of both neutral and cationic species were investigated and compared with the corresponding isomeric o-quinodimethane system.

Chihiro Sato, Shuichi Suzuki, Keiji Okada, and Masatoshi Kozaki*

Page No. - Page No.

Preparation and Properties of a Polycyclic $p$-Quinodimethane with Two Oxygen Bridges and its Radical Cation in Comparison with the Isomeric o-Quinodimethane 